\author{
Anamaria Marcon Venson
}

Universidade Federal de Santa Catarina, Florianópolis, SC, Brasil

\title{
Tráfico de pessoas para exploração sexual? Uma análise de processos-crime (1995-2012)
}

Resumo: Este artigo analisa processos-crime constituídos em função da operacionalização do artigo 231 do código penal brasileiro que define o crime de tráfico internacional de pessoa para fim de exploração sexual. Foram submetidos à análise 12 "casos" investigados/processados/ julgados entre os anos 1995 e 2012. As metodologias utilizadas foram pensadas a partir do campo epistemológico feminista: as categorias de análise são gênero, discursividade e processos de subjetivação. Esta pesquisa mostra como o combate ao tráfico de pessoas tem se materializado como uma técnica de combate à prostituição e às prostitutas.

Palovras-chave: Tráfico de pessoas; Exploração sexual; Prostituição; Trabalho.

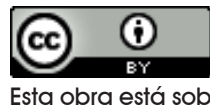

Esta obra está sob licença Creative Commons.

'Quando as palavras aparecem em itálico no corpo do texto, significa que foram recortadas de minhas fontes de pesquisa.

2 Uso o feminino para denotar a coletividade.
A proposta deste artigo é pensar a definição de tráfico internacional de pessoa para fim de exploração sexual disposta em nosso código penal e mostrar sua falibilidade através da análise de 12 processos-crime recentes (19952012) que se constituíram em função de sua operacionalização. Uma preocupação que move minhas perguntas é o reconhecimento de uma certa ordem de saber que anuncia que um dos empecilhos do combate ao tráfico de pessoas é que as vítimas não se consideram vítimas. ${ }^{1}$ Tal constatação aparece com frequência na fala de policiais, operadoras ${ }^{2}$ jurídicas e funcionárias do governo implicadas no trabalho de combate. Há muitos complicadores nessa discursividade $e$, entre os argumentos que tornam tal constatação incomodativa, destaco que há um significativo número de pesquisas acadêmicas a respeito de projetos de deslocamento transnacional que traz entendimentos diferentes das perspectivas "oficiais".

No Brasil, há uma diversidade de publicações feministas sobre projetos de mobilidade que têm mostrado muIheres participando ativamente em processos migratórios 
${ }^{3} \mathrm{O}$ feminismo não é e nunca fol um movimento unívoco. Reconheço a historicidade de uma certa perspectiva feminista que entende a prostituição não como um trabalho, mas como um exemplo emblemático da exploração patriarcal. Minhas problematizações partem de uma perspectiva feminista diversa, afinada com a noção de autodeterminação feminina e comprometida com a garantia de direitos sociais para pessoas adultas que se envolvem voluntariamente no campo laboral sexual.
(Carmen GREGORIO GIL, 2007; Gláucia de Oliveira ASSIS, 2007). Há, também, uma variedade de estudos mostrando mulheres se deslocando para se inserir no campo laboral sexual, porém, sem trazer aquelas cenas de horror difundidas pelo discurso dominante sobre o tráfico (Thaddeus Gregory BLANCHETTE; Ana Paula da SILVA, 2005). Resultados das pesquisas brasileiras encontram resultados de pesquisas produzidas por feministas de outros países fora do eixo norte (Sealing CHENG, 2010; Kamala KEMPADOO; Jo DOEZEMA, 1998; Susanne THORBEK; Bandana PATTANAIK, 2002; John FREDERICK, 2005). E até mesmo pesquisas feministas específicas sobre tráfico de pessoas não produzem resultados que encontram o discurso mais visibilizado sobre tráfico (Nick MAl, 2012). Há, ainda, pesquisas brasileiras apontando simplificações que formulam a categoria turismo sexual, que aparece associada ao tráfico no discurso dominante (Adriana PISCITELLI, 2007).

Minhas perguntas são, portanto, pensadas a partir do dissenso entre pesquisas acadêmicas feministas comprometidas com os direitos de mobilidade e de autodeterminação das mulheres ${ }^{3}$ e o discurso mais difundido sobre o tráfico, que nos aterroriza com imagens de mulheres sequestradas e forçadas a se prostituírem em bordéis estrangeiros.

Comprometida com minhas perguntas de pesquisa, arranjadas em jogo com minhas posições metodológicas devo alertar que os processos-crime que submeti à análise não podem ser entendidos como "representativos" das táticas de combate ao tráfico, mas, sim, como uma indicação da racionalidade que move práticas de combate no Brasil, afinal, há uma certa homogeneização das práticas policiais e do debate judicial. Submeti à análise 12 processos-crime inteiros, desde os inquéritos policiais até o momento em que se encontravam na data da coleta, produzidos nos estados de Goiás e Ceará entre os anos 1995 e 2012 . Segundo o ministério da justiça, no período de 2005 a 2011 foram abertos (distribuídos) 91 processos-crime a respeito de tráfico internacional. É importante notar que o número de registros policiais e de justiça a respeito de tráfico de pessoas aumentou drasticamente em relação aos anos 1990.

\section{Definições legais brasileiras - um panorama}

No código penal brasileiro, a definição de tráfico de pessoas se manifesta em relação necessária com a prostituição. Apesar da visível profusão discursiva que diz o tráfico como atentado aos direitos humanos, há, hoje, extensa bibliografia crítica à formulação dessa categoria (Nandita SHARMA, 2005), assim como o pânico em relação às "escravas brancas" foi também alvo de críticas feministas um século 
atrás. A discursividade que constituiu a prostituição como um problema foi possível através da medicalização e do policiamento da sexualidade; e o tráfico tornou-se dizível entrelaçado aos discursos médico e policialesco investidos no rechaço à prostituição.

Na redação do código criminal do Império do Brazil de 1830, a prostituição não se constituía como um problema. No entanto, já é visível a desqualificação de quem exercia essa atividade, já que a única referência feita a tal prática está colocada no artigo sobre estupro, onde aparece uma pena diferenciada caso o crime fosse cometido contra uma mulher honesta ou contra uma prostituta. Em minhas fontes de pesquisa, produzidas mais de um século depois, notei reedições desses entendimentos:

propósito de exercício do meretrício; aliciamento de diversas mulheres para a prática de sexo; finalidade de exercício do meretrício; degradação moral a que são submetidas as vítimas; conduta e personalidade maculadas, pois se dedica ao exercício da prostituição; conduta social e personalidade totalmente desviadas; [as vítimas] se apresentam volúveis; risco concreto à ordem pública; Débora é honesta; não se adaptou ao meretrício e quis retornar; atraídas e deslumbradas pela proposta; seduzida por proposta de lucro fácil; iludido a vítima com a promessa de que esta ganharia muito dinheiro no exterior; alegação de ganho fácil; seduzida com a referida proposta, mormente em vista dos lucros; atraída para fins de prostituição; aliciamento de mulheres para fins do exercício do meretrício no exterior, para isso havendo aliciado as mulheres solteiras daquela cidade e agora estando a fazê-lo com as casadas.

Ela Wiecko Volkmer de CASTILHO (2008) analisou sentenças judiciais recentes sobre tráfico de pessoas e apontou que, sobre as trabalhadoras do sexo posicionadas como vítimas nos processos, recaem desqualificações morais por parte das julgadoras. O entendimento de que as mulheres inseridas no campo laboral sexual são débeis e doentes é recorrente, como, por exemplo, quando se fala em mulheres seduzidas, atraídas e deslumbradas, degradação moral ou personalidade maculada, mas, ao mesmo tempo, de modo geral, a preocupação central não é exatamente com mulheres passivas aliciadas, mas com um certo comportamento desobediente, que coloca em risco a ordem pública, afinal, parece que elas têm propósito, escopo, exercem, praticam, têm finalidade, retornam, pensam no dinheiro, no lucro. Aparece uma certa "atividade" que está paradoxalmente contida na noção de tráfico.

A tensão entre as articulações "prostituta desviada infratora" e "prostituta vítima passiva" é justamente o que 
sustenta o combate à prostituição. Encontrei, por exemplo, condenações por tentativa de tráfico justificadas pela suposição de que as trabalhadoras são, muitas vezes, submetidas a regime de escravidão sexual, porém, sem nenhuma indicação, nos processos-crime, a respeito de como eram as condições de trabalho de tais mulheres no estrangeiro. Isso nos obriga a desafiar tal colocação e apontar que ela é, de fato, uma repetição irrefletida do difundido e dominante discurso sobre o tráfico e que não significa, necessariamente, uma análise das provas construídas no inquérito policial ou no âmbito judicial. Parece que tais exageros são efeitos próprios daquela tensão que sustenta os pânicos em relação à prostituição: é difícil convencer as funcionárias da lei de que as trabalhadoras do sexo têm direitos humanos como quaisquer outras pessoas.

Encontrei uma espécie de primeiro conceito de tráfico na legislação brasileira em Annotações Theorico-praticas ao Codigo Penal do Brasil, de Antonio BENTO DE FARIA, publicada em 1929. Antes de se reportar ao texto do código, (0) afamad(o) jurista explica que o tráfico de brancas havia sido estudado pelo governo francês, que promoveu uma conferência internacional em Paris, em 1902, na qual o Brasil tomou parte. Tal conferência, sob a presidência do ministro das relações exteriores da França, resultou no tratado internacional para eliminação do tráfico de escravas brancas de 1904, ratificado pelo Brasil. O autor explicita que as resoluções de tal conferência foram de ordem administrativa: vigilância internacional, extradição de culpad(o)s e repatriação das vítimas.

Em 1915, rearranjou-se a redação do código penal de 1890 trazendo, pela primeira vez no ordenamento brasileiro, uma espécie de definição de tráfico, no interior do artigo 278 , em jogo com o artigo 277. O artigo 277 penalizava facilitar a prostituição de outrem. O primeiro parágrafo do artigo 278 , sobre casas de tolerância, falava em desencaminhar mulheres e sinaliza preocupações com deslocamentos de mulheres para prostituição, ainda que com o seu consentimento:

\begin{abstract}
Alliciar, atrair ou desencaminhar, para satisfazer as paixões lascivas de outrem, qualquer mulher menor, ou não, mesmo com o seu consentimento; aliciar, atrair ou desencaminhar, para satisfazer ás paixões lascivas de outrem, qualquer mulher maior, virgem ou não, empregando para esse fim ameaça, violência, fraude, engano, abuso de poder ou qualquer outro meio de coacção; de reter, por qualquer dos meios acima referidos, ainda mesmo por causa de dividas contrahidas, qualquer mulher, maior ou menor, virgem ou não, em casa de lenocínio, obrigal-a [sic] a entregarse á prostituição.
\end{abstract}

574 Estudos Feministas, Florianópolis, 25(2): 571-591, maio-agosto/2017 
Os comentários explicativos do artigo, elaborados pel(o) afamad(o) jurista De Faria, explicitam o fato de a prostituição ser obrigatoriamente a entrega do corpo [feminino] por paga e sem escolha. O mesmo autor, talvez em um tropeço retórico, explica que as vítimas não acusam [o negociante]. Mas, também, em minhas fontes de pesquisa, encontrei refrões da mesma ordem: as vítimas, na maioria dos casos, nunca depõem contra os aliciadores. Frases com esse sentido são recorrentes nos processos-crime e inquéritos recentes tratando de tráfico para exploração sexual.

Dentro da lógica de que uma prostituta era sempre presa, ou de sua debilidade física e moral, ou de algum(ns) explorador(es ) perverso(s), qualquer mulher estrangeira que se dedicasse à prostituição, voluntariamente ou não, e que não fosse benquista em seus círculos de sociabilidade, poderia ser facilmente repatriada em cumprimento da função estatal de "limpar" as capitais brasileiras para que o país pudesse, finalmente, ser aceito no rol das nações civilizadas. Pouco importa se elas consentem ou não, porque não são os direitos delas que se está tentando proteger. E a mesma lógica tem sido ainda colocada em discurso no Brasil nos dias atuais, transmutada na máxima de que o consentimento da vítima é irrelevante para configurar crime de tráfico.

Em 1940, um novo código penal brasileiro foi elaborado. Pela primeira vez, o tráfico ganha um artigo específico. O artigo 231 dizia: Promover ou facilitar a entrada, no território nacional, de mulher que nêle venha a exercer a prostituição, ou a saída de mulher que vá exercê-la no estrangeiro. Pena [...]. Se a apontada vítima tivesse entre 14 e 18 anos de idade, se (o) agente fosse ascendente, descendente, marido, irmão, tutor ou curador ou afim, se houvesse emprego de violência, grave ameaça ou fraude, ou se fosse cometido com fim de lucro, aumentava-se a pena.

O tráfico, aí, é colocado como uma modalidade de lenocínio. O exercício da prostituição não é penalizado, tampouco a compra de tal serviço, mas qualquer ajuda ou facilitação são desencorajadas. Essa disposição confusa de permissões e proibições parece estratégica para satisfazer as mesmas contraditórias demandas do século XIX, que se faziam em torno da tensão entre as concepções da prostituta como "vítima passiva" e como "infratora da moralidade". Em meados do século XX, não havia que se pensar em "agência feminina", como se faz hoje, tampouco em "direito ao próprio corpo", pauta dos movimentos feministas de 1960, pois as mulheres que se dedicavam a tais atividades eram simplesmente desconsideradas no discurso jurídico. Não somente elas não participavam do debate, como nem sequer eram consideradas sujeitas. 
Apesar de um certo número de modificações terem sido negociadas e conquistadas, a definição de tráfico que compõe o código penal atualizado não é tão diferente daquela dos anos 1940. A definição de tráfico continua disposta no artigo 231 e compõe a parte (título) que trata dos crimes contra a dignidade sexual. Dentro dessa parte, há um capítulo que trata do lenocínio e do tráfico de pessoa para fim de prostituição ou outra forma de exploração sexual, que traz definições dos seguintes crimes: mediação para servir a lascívia de outrem (artigo 227), favorecimento da prostituição ou outra forma de exploração sexual (artigo 228), casa de prostituição (artigo 229), rufianismo (artigo 230), tráfico internacional de pessoa para fim de exploração sexual (artigo 231), tráfico interno de pessoa para fim de exploração sexual (artigo 231-A).

A redação de tal capítulo teve várias modificações nos anos 2005 e 2009 em função de lutas pela constitucionalização do código penal, mas, também, em função da ratificação do protocolo de Palermo, que é uma normativa supranacional sobre o crime organizado negociada no ano 2000 (UNODC, 2000). Em 2005, por exemplo, o tráfico internacional de pessoa(s) tomou o lugar do antigo dispositivo sobre tráfico internacional de mulheres e foi reconhecida a existência de tráfico interno. Contudo, o código manteve o vínculo explícito entre tráfico e prostituição, diferentemente da normativa supranacional, que define tráfico como deslocamento forçado, sob engano ou violência, para exploração de trabalhos em geral.

Uma outra modificação recente foi a inclusão, no código, da categoria exploração sexual, que vinha sendo debatida no Brasil, no contexto de reivindicação de direitos para crianças e adolescentes, desde os anos 1990 (Marcia Anita SPRANDEL; Guilherme Mansur DIAS, 2010). Certamente que a inclusão dessa categoria está também relacionada com tentativas de adequação ao protocolo de Palermo, ratificado pelo Brasil em 2004, que traz textualmente uma preocupação especial com a exploração sexual, embora deixe indefinido o significado de tal prática por falta de consenso (Bridget ANDERSON; Julia O'CONNELL DAVIDSON, 2002). Onde antes se falava, no código, em prostituição, agora se fala em prostituição ou outra forma de exploração sexual.

Tal categoria, apropriada no debate sobre o combate ao tráfico, acabou produzindo equívocos em função da confusão entre trabalho sexual de pessoas adultas e exploração sexual infantil. A categoria exploração sexual é recente e ainda não há, para ela, em função de disputas de interesses antagônicos, uma definição precisa. Sem definição consensual a respeito do que seja exploração sexual, as questões parecem se resolver em torno da ideia de prostituição simplesmente.

576 Estudos Feministas, Florianópolis, 25(2): 571-591, maio-agosto/2017 
O artigo 231 define que alguém comete o crime de tráfico internacional de pessoa quando promove ou facilita a entrada, no território nacional, de alguém que nele venha exercer a prostituição ou outra forma de exploração sexual, ou a saída de alguém que vá exercê-la no estrangeiro. $O$ emprego de violência, grave ameaça ou fraude e fins de lucro não são definidores do tráfico e são tratados como elementos adicionais que podem dar causa ao aumento de pena. Uma outra questão colocada é que favorecer [a prostituição] é induzir, atrair, facilitar; traficar é promover ou facilitar o deslocamento (entre fronteiras nacionais ou dentro do país). Essa discursividade complica a legitimidade de associações de ajuda mútua (PISCITELLI, 2008) organizadas entre as trabalhadoras, que podem ser acusadas de facilitação ou de conivência com o tráfico de pessoas. Ora, com relação ao tráfico, o que o código penaliza é o deslocamento para prostituição.

As discussões em torno da formulação do protocolo de Palermo pensavam nos casos em que alguém promove o deslocamento de uma pessoa, encorajando-a a entrar em acordo quanto ao pagamento de dívidas altas, enganandoa sobre o quanto vai ganhar e sobre as condições de trabalho no lugar de destino. O debate pensava em pessoas que, depois de viajar, se encontram em uma situação em que é impossível pagar tal dívida, submetendo-se, assim, a condições de trabalho que poderiam ser entendidas na ordem de "escravatura". Apesar dos vários problemas do protocolo, que foi, afinal, formulado a partir da discussão sobre crime organizado transnacional e, não, necessariamente, perspectivado por preocupações com direitos humanos, tal normativa pensava em "processos" de deslocamento de um país a outro, ou entre vários países, que combinavam atividades que não seriam necessariamente entendidas como crime se tomadas individualmente, mas que, em conjunto, colocavam pessoas em situação de exploração. O tráfico não seria uma ação, mas um conjunto de ações, um processo com várias fases: recrutamento, transporte e controle no lugar de destino.

O artigo 231 do código penal, dentro do contexto proibicionista da prostituição que garante sua aplicação, além de confundir prostituição e exploração sexual, não leva em consideração a noção de "processo" pensada no protocolo. Fala em entrada ou saída de prostitutas do território nacional. É essa a atividade criminalizada. E a análise de minhas fontes de pesquisa mostra que as funcionárias da lei, para dar aplicação ao artigo 231, são obrigadas a acatar o entendimento prévio de que o exercício da prostituição é exploratório em si mesmo.

Em minhas fontes, encontrei, repetidos à exaustão, trechos como os seguintes: 
${ }^{4}$ Todos os nomes de pessoas que aparecem nos recortes de minhas fontes são fictícios. conduzidas ao meretrício; viagem das aliciadas para o exercício do meretrício; saída de mulher do território nacional visando ao exercício da prostituição; aliciado mulheres para a prática da prostituição; confirmou a participação da família em incentivos à prostituição; naquele país, [a acusada] respondeu tão somente por exercício ilícito da prostituição; [acusada] indiciada [no estrangeiro] por exercício ilegal da prostituição; aliciamento de garotas nacionais.

O que especializa a definição penal de tráfico internacional em relação aos crimes de favorecimento da prostituição e tráfico interno é a meta geográfica. Não importa as condições de deslocamento ou de trabalho no lugar de destino, ainda que se trate de um contrato formalizado para trabalhar em país onde a prostituição é atividade regulamentada.

É esse o trabalho das funcionárias da lei sob o mando do artigo 231 : para dar-lhe funcionamento, são obrigadas a justificarem, previamente, o entendimento de que prostituição é violência, dando, assim, uma ideia de "processo" para nossa disparatada definição de tráfico. Se prostituição é violência, é exploração em si, basta apenas o vislumbre de tal atividade para que se produza uma viagem como tráfico. É porque há uma longa história de inscrição da prostituição no universo do ilícito que a prática do 231 é possível.

\section{Operacionalização do artigo 231 em processos-crime}

O registro policial mais antigo que encontrei em minhas fontes ${ }^{4}$ data de meados da década de 1990:

Em 29 de novembro de 1995, [...] Fabiana, Marcela e a menor Bianca [...] uma vez que as duas últimas estavam portando carteira de identidade com dados falsos, e com as mesmas obtiveram passaporte, que também portavam, e, com eles, pretendiam ir para a Espanha, com o fim de se prostituírem, convencidas pela primeira.

O relatório de inquérito da delegacia de polícia de outubro de $1996 \mathrm{diz}$ :

Este procedimento foi instaurado para apurar o tráfico de mulheres para o exterior, praticado por Fabiana. [...] havendo suspeitas de estar agenciando mulheres para serem levadas para a Espanha, onde se dedicariam à prostituição.

Em novembro de 1996, o minis-tério público federal elabora a denúncia: 
${ }^{5}$ Bianca não foi apontada como suposta vítima pelo ministério público federal nesse processo, mas em outro.
A primeira denunciada atuou, como já o fez em outras ocasiões, como agenciadora, no Brasil, a pedido de Carla (residente na França), para enviar a segunda denunciada à Cidade Espanhola, onde deveria 'trabalhar' na casa de prostituição de Douglas, local onde já se encontram outras moças brasileiras [...] Dessa forma, restou incontroverso que a trama engendrada por elas, de falsificar e usar certidão de nascimento, identidade e passaporte, teve como finalidade exclusiva favorecer a ida da segunda denunciada Marcela - para a Cidade Espanhola, onde deveria se prostituir.

Nesse processo, como também em outros, trabalhar aparece entre aspas, porque a prostituição é atividade tolerada, mas não é entendida como trabalho pelas funcionárias da lei. Nessa época, o tráfico de pessoas ainda não era um assunto midiático de destaque e tampouco um alvo prioritário de políticas públicas no Brasil. A investigação policial se faz a partir de uma preocupação com falsificação de documentos, que teria como fim possibilitar a viagem de uma mulher, Marcela, à época, civilmente menor de idade (menos de 21 anos) e penalmente maior de idade (mais que 18 anos). ${ }^{5}$ Naquela época, era necessário completar 21 anos de idade para obter o passaporte sem autorização de responsável. Nesse caso específico, Marcela foi, ao mesmo tempo e no mesmo processo, acusada/condenada por falsificação de documentos e apontada como vítima de tráfico de mulheres, já que a também jovem mulher Fabiana foi condenada por tentativa de tráfico, pois Marcela nem sequer viajou para o estrangeiro.

Encontrei uma variedade de casos de tentativas, o que também implica condenação. É comum encontrar trechos explicando que acusadas e apontadas como supostas vítimas tentavam embarcar com a finalidade de se prostituírem. Na prática policial, tráfico é o mesmo que favorecimento da prostituição. Assim como o combate ao tráfico compõe o combate à prostituição, também se mistura ao combate ao turismo sexual, categoria de difícil definição e que não constitui crime no Brasil. Em 2003, no estado do Ceará, inicia-se uma investigação no âmbito da polícia civil, partindo de confusões elaboradas sobre prostituição e turismo sexual, que dão espaço, lugar, que legitimam a aplicação da categoria tráfico de mulheres:

[...] embasadas suspeitas do envolvimento de Caio nos crimes de favorecimento da prostituição, rufianismo e tráfico internacional de mulheres. [...] apresentamos dois bilhetes deixados por uma garota na casa de Caio, afirmando que queria viajar para a Espanha, para trabalhar com sua irmã, que lá estaria, [...] o

Estudos Feministas, Florianópolis, 25(2): 571-591, maio-agosto/2017 579 
caso que investigamos é de extrema relevância de interesse social, uma vez que várias famílias foram lesadas [...] manutenção da segurança pública requer ao poder judiciário meios legais para a viabilização do exercício de sua função - até porque, atualmente, é uma das metas do governo estadual o combate ao turismo sexual, à prostituição e todos os seus desdobramentos, razão pela qual apelamos para a vossa valorosa e essencial colaboração, assim como a do ministério público.

Turismo sexual não constitui crime no Brasil e tampouco há consenso nas Ciências Humanas sobre o que seria tal prática, mas a polícia justifica o combate ao tráfico com o argumento de que é uma das metas do governo estadual o combate ao turismo sexual, à prostituição e todos os seus desdobramentos. Nada está nas entrelinhas, tudo pode ser visto: tal investigação ganhou existência sobre o objetivo de combate à prostituição e todos os seus desdobramentos. A noção de tráfico foi ganhando espaço de aplicação dentro do combate à prostituição e ao turismo sexual, espaço esse produzido não somente pela polícia, mas por instituições outras, como, por exemplo, governos estaduais. Não é que a categoria tráfico trouxe o combate à prostituição. Há todo um histórico de combate policial à prostituição e às prostitutas no Brasil e o tráfico foi agregado a uma discursividade que já estava em curso.

Se, na década de 1990, falava-se em agenciamento de mulheres para serem levadas para país $X$, onde se dedicariam à prostituição, em prática de aliciamento de mulheres para exercer a prostituição no exterior, falava-se em convites; com o tempo, passa-se a explicar, a dizer o tráfico de maneiras mais elaboradas:

organização que se dedicava à imigração ilegal de mulheres brasileiras para a prática da prostituição, rede internacional de prostituição de mulheres, rede de traficantes internacionais de pessoas.

No entanto, o fundamento continua o mesmo: tratase de combate à prostituição, que se transformou em combate ao tráfico de mulheres através da modificação de termos, porém não difere substancialmente daquela antiga resposta a ansiedades em relação à prostituição em si. Uma descrição comum dos casos tratados nos processos aparece no trecho do ministério público federal de julho de 2004:

Desde meados de abril de 2004, nesta capital, os denunciados, em comunhão de ações e unidades de desígnios, mediante oferta de vantagens financeiras tendentes a ludibriar as vítimas, promoveram e facilitaram e tentaram promover e facilitar a saída de 
mulheres do território nacional visando ao exercício da prostituição, por elas, em país estrangeiro, com escopo de lucrar com a exploração sexual destas mulheres.

Tal é a descrição geral que aparece nos processos e estava já elaborada em 2004. Um parágrafo emblemático, dado que é assim repetido à exaustão nos processos: a polícia produz suas condições de existência, a imprensa o divulga, o debate judicial o autentica. No entanto, a ordem dos termos da denúncia deve ser explicada: o crime é, por si só, o fato de que promoveram e facilitaram e tentaram promover e facilitar a saída de mulheres do território nacional visando ao exercício da prostituição, por elas, em país estrangeiro. A existência de uma suposta "máfia", "quadrilha", "organização criminosa", organização intencionada (dolo), traduzida na explicação de que os denunciados, em comunhão de ações e unidades de desígnios, é uma justificativa adicional, não é necessária para a caracterização de tráfico de acordo com o texto do código penal. A mesma situação, desde que não se mencionasse que o destino era o país estrangeiro, poderia ser entendida como crime de favorecimento. Tampouco o lucro é elemento que condiciona a caraterização, já que o próprio código o prevê como causa de aumento de pena, apenas.

Falida nos próprios processos-crime, a noção de que as envolvidas nada sabem a respeito do trabalho no estrangeiro, desenvolve-se uma nova discursividade. Essa constatação tem dado lugar à justificativa, por parte das funcionárias da lei, de que o consentimento da vítima é irrelevante para configurar crime de tráfico. É montado, a priori, o argumento de que não é possível obter vantagens financeiras trabaIhando como prostituta no estrangeiro, já que se supõe que elas estariam presas por dívidas impagáveis. Esse entendimento é tomado como regra e sem necessidade de verificação. Prostituição não é entendida no universo de sentido do trabalho, mas, sim, no universo de sentido do abuso, do crime. Portanto, seria incoerente, dentro dessa malha de saber, admitir que uma pessoa pode lucrar ou ter algum benefício com seu próprio trabalho sexual. Qualquer apontamento, por parte das acusadas, a respeito de vantagens financeiras, é entendido como "engano" - tendente a ludibriar as vítimas. Porém, o engano, que aparece enlaçado à noção de vulnerabilidade, também não é elemento definidor de tráfico, mas apenas causa de aumento de pena.

Quando abrimos os autos de um processo-crime, o primeiro texto que se apresenta é o primeiro parágrafo da denúncia do ministério público federal, como aquele parágrafo emblemático. Esse primeiro parágrafo é sempre, obviamente, uma repetição do mandatório artigo 231 do código 
penal, porém com a qualificação, com o poder autorizado, não de prever, mas de traduzir situações da vida quotidiana para o vocabulário do crime.

Aquilo que está colocado nos primeiros parágrafos das denúncias é o que aparece, em geral, nas manchetes midiáticas, como se fosse resultado de investigações que procuram por fraude ou por escravidão. Porém, não é isso que fica evidente nos processos-crime que analiso. Na imprensa, aparece o discurso da polícia, o discurso das investigações, ainda que sem julgamento. Nas estatísticas oficiais, aparecem contabilizados juntos casos de favorecimento, rufianismo e tráfico, já que fica evidente que, nos processos sobre tráfico, elaborados em torno daquela definição disparatada do código penal, tais questões se misturam. E é fácil entender como as estatísticas de tráfico de pessoas são infladas (BLANCHETTE; SILVA, 2012; Ronald WEITZER, 2014): esse somatório chega às manchetes como se houvesse uma proliferação descontrolada de casos de tráfico, porém naquele entendimento mais difundido, que condiciona o "fenômeno" a situações envolvendo engano e prostituição forçada. As fontes que submeti à análise não se constituem necessariamente de descrições de violência, coerção ou engano, mas são contabilizadas como casos de tráfico em pesquisas institucionais que inflam aquela ideia de horror ao redor da prostituição. Corroborando os resultados de minha pesquisa, há uma variedade de estudos antropológicos apontando que aqueles casos extremos difundidos no discurso dominante são uma raridade (PISCITELLI, 2012).

Essas elaborações têm implicações práticas violentas contra mulheres pobres que desejam viajar para se inserir no campo laboral sexual, ainda que planejem projetos de mobilidade para países onde a prostituição é regulamentada. Em junho de 2004, com a autenticação da justiça federal, a polícia adiciona informação ao processo:

Para efeito da ciência do juiz federal, informo que o esquema de agenciamento era maior do que pensávamos, posto que ficamos sabendo na data de hoje que, vinculada à reserva da informante Natália, havia a de outras 05 (cinco) pessoas, todas mulheres, cujas passagens foram compradas em Cidade Espanhola.

Em outro processo, encontrei um formulário de denúncias, datado de outubro de 2004, assim dizendo:

O denunciante [que é membro do ministério público federal] informa que Eduardo é muito conhecido naquela cidade [Cidade do estado de Goiás], tem uma irmã que é dona de um prostíbulo na Europa e com certa frequência viabiliza a ida de mulheres para Suíça a fim de serem exploradas sexualmente. Somente

582 Estudos Feministas, Florianópolis, 25(2): 571-591, maio-agosto/2017 
que ele tem conhecimento, já foram enviadas 17 mulheres. OBS: o informante noticia que as mulheres estarão indo amanhã e poderão embarcar em Goiânia ou Brasília, sendo certo que antes de irem para a Suíça, passarão pela ltália.

Sob o argumento de proteger as mulheres, o que se está proibindo é a saída do Brasil de mulheres brasileiras trabalhadoras do sexo. Armam-se flagrantes sensacionais em aeroportos internacionais e as envolvidas são obrigadas a confessar suas intenções de inserção no campo laboral sexual estrangeiro, são colocadas na difícil posição de justificar seus projetos: se por vulnerabilidade/fraqueza, se por engano/tolice, ou se voluntariamente e por desvio moral. Ora, a prostituição ainda é socialmente associada ao universo do ilícito. Em julho de 2005, Júlio foi condenado por:

[...] a ação do acusado limitou-se à apresentação da aliciada Lara ao co-réu Renato. [...] não agiu com intenção de lucro, tendo apenas colaborado com a pessoa que demonstrou interesse em viajar para a Europa com vistas ao exercício da prostituição [...] consequências não são graves [...] não houve consumação.

A lógica do artigo 231 e o entendimento das funcionárias da lei que o operam é impedir a saída do país de pessoas que tenham intenções de se inserir no campo laboral sexual no estrangeiro. É a mesma lógica do século XIX: viajar para a Europa com vistas ao exercício da prostituição é proibido, assim como participar de qualquer modo dos preparativos de tal viagem é ato criminoso, já que mesmo os casos em que não se age com intenção de lucro são punidos. Tais casos são contabilizados como tráfico e compõem os números forjados daquela imagem de terror do discurso mais difundido. Em julho de 2005, a polícia federal se justifica:

Chegou ao nosso conhecimento notícia de que Eduardo era versado na prática do aliciamento de mulheres para fins do exercício do meretrício no exterior, para isso havendo aliciado as mulheres solteiras daquela cidade e agora estando a fazê-lo com as casadas, pelo que logo nos colocamos a caminho da Cidade do estado de Goiás, colhendo depoimento do representante ministerial no local.

A preocupação da polícia se elabora em torno da ideia de que, antes, se aliciava as mulheres solteiras, provavelmente se referindo a trabalhadoras do sexo, afinal, se imagina que tais profissionais são sempre solteiras, livres, sem dono e ao mesmo tempo "públicas"; mas que, a partir de certo momento, tal esquema estaria atraindo até mesmo as mulheres casadas, entendendo que seriam já propriedade de seus maridos, que seriam "de família", "direitas" e não "perdidas", fazendo do 
tráfico um problema ainda mais grave no seu parecer. Em dezembro de 2005, a polícia federal explica que:

Eduardo, após o aliciamento de mulheres em Cidade do estado de Goiás, cuida de enviá-las à Suíça, onde as irmãs e $\circ$ [citado] acima descritos as distribuem para o exercício do meretrício. [...] A polícia de Região Suíça envia então os documentos em anexo, dos quais se conclui o aliciamento de diversas mulheres para a prática de sexo [...].

Sob a justificativa do combate ao tráfico, a polícia está autorizada a controlar a prática de sexo das mulheres brasileiras, a polícia está autorizada a determinar quais e em que condições as mulheres brasileiras podem performatizar a prática de sexo. Não é difícil entender as referências a mulheres solteiras e casadas, portanto.

Em outubro de 2005, o ministério público federal junta informações da polícia de Região Suíça

dando conta da existência de aliciamento de garotas nacionais para o exercício da prostituição no exterior. [...] Corroborando a prática do tráfico de seres humanos para fins de prostituição [...].

Lemos para fins de prostituição como se prostituição em si, ou mesmo a prática de sexo, fossem o problema. Em 2005, já aparecem termos da discussão do plano internacional: fala-se em tráfico de seres humanos. Evoca-se termos internacionalizados para nos convencer da importância da denúncia, porém, com definições obedientes à lei nacional, o que se nota na menção ao termo para fins de prostituição.

Ao mesmo tempo em que ultrapassam os sentidos das normativas supranacionais, usa-se, também, termos que extrapolam o próprio código penal, como se nota na colocação aliciamento de garotas nacionais para o exercício da prostituição. Os textos da polícia do ministério público e da justiça federal estão repletos de termos inventados por elas próprias para explicar o tráfico e que não são constantes de nenhuma normativa legal. Encontrei, recorrentemente, a palavra meretrício e a palavra garotas para se referir a mulheres apontadas como supostas vítimas. A palavra prostituição é declarada no código penal atual, mas vale lembrar que seu uso também teve motivação no contexto de investimentos morais no século XIX. Tampouco prática de sexo, que apareceu citada no vocabulário da polícia, é um termo legal. Tais extrapolações também formulam sentidos à prostituição. E quando o ministério público escreve que o crime é facilitar a saída da vítima, está aí produzindo subjetividades também, do mesmo modo que quando a polícia fala em mulheres solteiras e mulheres casadas.

584 Estudos Feministas, Florianópolis, 25(2): 571-591, maio-agosto/2017 
Nessa racionalidade, todas as mulheres que se envolvem em prostituição estão sob suspeita e é essa a lógica que move as denúncias, como lemos na elaboração da justiça federal, em abril de 2006: A própria ré [...] já foi vítima do mesmo crime em que ora é acusada, pois foi aliciada no final de 2001 para o exercício da prostituição na Espanha. A conclusão de que a acusada é ou foi envolvida no campo laboral sexual ela própria pôde servir, então, de reforço de prova para sua condenação como traficante de outras mulheres.

Em abril de 2006, tendo por objeto lenocínio e tráfico de pessoas, um inquérito policial mostra como se transformam suspeitas imaginadas em pânicos compartilhados:

informa a prática do tráfico internacional de mulheres e comunica denúncia sobre agenciamento de três jovens mulheres para trabalhar na Espanha, podendo as mesmas estarem sendo iludidas e forçadas e se prostituir.

No meio do processo, encontro documentos datados de vários anos antes da formalização do inquérito policial, entre eles um documento (peça) que assim diz:

O ministério público federal requisita instauração de inquérito policial para cabal apuração dos fatos noticiados nos documentos em anexo, à vista de possível prática de crime insculpido no artigo 231 do código penal. Ressalto que as supostas vítimas do tráfico já se encontram em território nacional, se preparando para retornar ao exterior, conforme informado ao ministério público federal.

O que é ressaltado é o fato de que as supostas vítimas já se encontram em território nacional, se preparando para retornar ao exterior. A polícia e o ministério público, mandadas pelo código penal, e aprovadas pelo judiciário, agem, juntas, para impedir viagens de prostitutas. Para cumprir essa tarefa, colocam em discurso um entendimento embaraçoso, que nos confunde a respeito do alvo do combate: se são as tais traficantes ou se são as supostas vítimas. Afinal, é sobre essas últimas que recai a ação policial: elas devem ser impedidas de retornar ao exterior.

O combate ao tráfico tem colocado as mulheres pobres que planejam viajar para o estrangeiro sob suspeição generalizada. O que é também problemático no modo como o judiciário e a polícia têm tratado a prostituição é que qualquer pessoa que se envolva nesse processo de tráfego/deslocamento através de fronteiras, sabendo que se trata de viajantes que foram, são ou potencialmente serão trabalhadoras do sexo, pode ser acusada de crime de traficar pessoas. Quem perde direitos e oportunidades, portanto, são as próprias pessoas pobres que precisam da 
"ajuda" de alguém para poder viajar. A própria justiça fala em ajuda, em favores, em auxílio em diversas ocasiões. Em março de 2009, em segunda instância (onde são julgados os pedidos de reexame das sentenças), lemos o voto relator: o próprio apelante, em seu interrogatório judicial, admitiu ter auxiliado Lara na tentativa de deixar o Brasil para se prostituir na Espanha.

Basta a pessoa ter conhecimento da atividade para que se justifique a acusação/condenação, como se lê em relatório de atividades policiais datado de 2009: Alice encaminhou à prostituição na Suíça a brasileira Paula [irmã de Alice], enquanto João demonstrou claramente ter conhecimento da atividade ilícita de Alice. Não foram raros os casos em que uma amiga que indica outra para um trabalho, ou em que uma irmã que financia as passagens aéreas da outra, foi acusada, julgada e condenada por tráfico de pessoas. Alice, por exemplo, é trabalhadora do sexo e está sendo julgada por ter providenciado as passagens aéreas de suas irmãs Paula e Gisele, ambas adultas. O fato de serem irmãs serve, no entanto, para justificar desaprovação ainda maior por parte das funcionárias da lei, já que se coloca em discurso que as acusadas estão submetendo à prostituição pessoas de suas próprias famílias. No caso de Alice e Gisele, o ministério público adiciona, na denúncia, trechos de suas conversas ao telefone, onde Alice dá instruções à Gisele a respeito de como fazer as malas, como se vestir e o que dizer para a polícia de imigração. A transcrição dessa conversa constituiu indício de tráfico.

É comum encontrar processos-crime que tiveram lugar em função de uma denúncia (notícia de crime) anônima nas delegacias de polícia. A partir de tais denúncias, armase um flagrante no momento anterior ao embarque nos aeroportos. A polícia aborda as envolvidas e quem confessar conhecimento a respeito da pretensão da viagem para inserção no campo laboral sexual estrangeiro é apontada como criminosa. Em agosto de 2003, o ministério público federal demonstra como multiplicar as investigações e escrutinar as redes de ajuda:

[...] tendo em vista os indícios de que Janaína teria financiado a viagem de sua irmã, Isadora, para que a mesma, juntamente com Lara, fosse exercer o meretrício na Espanha, requeiro seja dado continuidade às investigações, com o fito de melhor averiguar a informação acima narrada, bem ainda para apurar a eventual participação de outros envolvidos na empreitada criminosa em referência, inclusive dos denunciados Renato, Rafaela, Júlio e Renata. [...] seja providenciada a extração do traslado dos presentes autos a fim

586 Estudos Feministas, Florianópolis, 25(2): 571-591, maio-agosto/2017 
de que seja instaurado, à parte, outro inquérito policial, visando apurar a responsabilidade de Luana e sua irmã Jaqueline, na promoção da saída de Renata e Janaína do território nacional, para o exercício da prostituição na Espanha, o que ocorreu, aproximadamente, no mês de março do corrente ano.

Os indícios de que fala o ministério público federal são a existência de uma operação de flagrante, oportunizada em função de uma notícia de crime anônima, e os relatos das apontadas como supostas vítimas. Tais relatos não são entendidos como prova do crime, mas como indícios que devem ser investigados e comprovados. Os documentos comprobatórios do crime, cuja apreensão está citada no trecho recortado do relatório policial, eram passagens aéreas e dinheiro. A eles foram juntados comprovantes de transferências bancárias onde constavam os nomes mencionados pelas pessoas flagradas no aeroporto. Tais comprovantes foram, portanto, convencionados como prova de crime porque em consonância com as confissões das envolvidas. São eles as provas de autoria e materialidade. As funcionárias da lei nada mencionam sobre o fato de apontarem para acusação Renata, por ter tentado facilitar a saída de Lara, e, ao mesmo tempo, Luana e Jaqueline, por terem facilitado a saída da própria Renata. Fiquei a imaginar os prejuízos de tantas trabaIhadoras, que, numa rede de ajudas, financiam as passagens aéreas umas das outras, passagens essas que são caras e que são perdidas por causa dos flagrantes policiais.

Entre as testemunhas de acusação nesse mesmo processo, figuram agentes de polícia que participaram do flagrante no aeroporto. Um "caso" bastante simples, porém emblemático do que encontrei nos processos em relação à atividade da polícia: uma notícia de crime, nesse caso, anônima, flagrante no aeroporto, práticas de fazer confessar o envolvimento com prostituição e delatação de nomes, coleta de documentos comprobatórios de viagem realizada ou combinada. Tudo isso não necessariamente na mesma ordem. Parece que são essas as operações policiais em geral.

Em julho de 2009, a definição convencionada de exploração sexual parece já estabilizada e é normalizada a equação entre prostituição e exploração. A polícia explica:

Trata o presente procedimento de investigação visando apurar autoria e materialidade de crime de aliciamento das brasileiras Juliana e Adriana para fins de exploração sexual na Espanha. Com o retorno das brasileiras do exterior foi possível reduzir a termo seus depoimentos, ambos convergindo no sentido de que foram conduzidas ao meretrício no exterior por 'Patrícia', sendo as despesas pagas por esta, mediante depósito em suas respectivas contas bancárias. 
O texto policial cita o número do artigo 231, porém cita como definição o texto do artigo 228 , que trata de favorecimento, quando diz aliciamento das brasileiras Juliana e Bianca para fins de exploração sexual. Trata-se, pois, da mesma questão. E essas produções são feitas com a conivência do ministério público, que relata em seguida:

Cuida-se de inquérito policial [...] para apurar possível crime contra a dignidade sexual [...], em tese, praticado por 'Patrícia', a qual teria aliciado Adriana e Juliana para exercerem o meretrício em Portugal, na boate $B$, de propriedade de Carlos.

Ficou constituído como fato, no processo-crime, que Patrícia, Juliana e Adriana trabalharam juntas no estrangeiro. Nesse mesmo documento (peça) do ministério público, aparece a fala traduzida de Juliana, apontada como suposta vítima, que teria dito, ainda em junho, que: [...] esclarece mais uma vez que Patrícia não era agenciadora, uma vez que fora a declarante que a procurou e disse que gostaria de trabalhar na Espanha [...]. Há vários outros exemplos de pessoas apontadas como supostas vítimas que teriam elaborado declarações semelhantes. No entanto, o ministério público federal, evocando a máxima de que o consentimento da vítima é irrelevante, escreve para a polícia federal, em junho de 2011 , dando instruções sobre como coletar as provas. Em setembro de 2009, a decisão da justiça federal autentica:

Importante salientar que a requerente, ao fornecer sua conta bancária para depósito do dinheiro necessário à aquisição da passagem aérea, colaborou para a prática criminosa, relegada à forma tentada. [...] Ademais, é sabido que tal conduta, consistente na prática do fato delituoso previsto no artigo 231 do código penal, o chamado tráfico de mulheres, é reiterada em nosso estado, ameaçando a ordem pública [...].

Traficar, aliciar, agenciar, ajudar, auxiliar, arregimentar, recrutar, convidar, indicar, facilitar, informar, promover são termos conjugados no mesmo sentido nos processos-crime. Se confundem no discurso das funcionárias da lei.

\section{Considerações finais}

Há extensa bibliografia crítica da categoria tráfico de pessoas. Comparações de narrativas sobre aquilo que foi chamado de "escravidão branca" no século XIX e sobre o tráfico de mulheres na contemporaneidade mostram que o discurso mais difundido sobre tráfico continua funcionando através de mitos culturais que constroem entendimentos a respeito de deslocamentos de mulheres para inserção no campo laboral sexual (DOEZEMA, 2000). Outras pesquisas 
explicam como a empreitada do "resgate de vítimas de tráfico" tem lugar como discurso moralizante que produz a sujeita que "ajuda" - aquela que "salva" mulheres da prostituição - e a sujeita que é "ajudada" - a "prostituta arrependida" -, perpetuando hierarquias sociais (Laura María AGUSTíN, 2007). Há análises de práticas atuais de combate ao tráfico que pontuam repetições dos esforços de resgate e recuperação de prostitutas no final do século XIX (Gretchen SODERLUND, 2005). E outras que mostram reapropriações daquilo que chamam de "mito das escravas brancas" em discursos antitráfico brasileiros atuais (SILVA; BLANCHETTE; Andressa Raylane BENTO, 2013). E há pesquisas etnográficas que concluem que as pessoas tidas como vítimas de tráfico pelo poder tutelar do estado raramente se identificam como tais porque, sendo tráfico de pessoas uma categoria administrativa e criminal, dificilmente garante acesso a direitos (PISCITELLI; Laura LOWENKRON, 2015). Em minha pesquisa, pretendi mostrar, através da análise de processos-crime, como o desenvolvimento de procedimentos policiais específicos para impedir a prostituição ganhou estatuto de técnica de combate ao tráfico.

\section{Referências}

ANDERSON, Bridget; O'CONNELL DAVIDSON, Julia. Trafficking: a Demand Led Problem? Stockholm: Save the Children, 2002.

AGUSTíN, Laura María. Sex at the Margins: Migration, Labour Markets and the Rescue Industry. Londres: Zed, 2007.

ASSIS, Gláucia de Oliveira. "Mulheres migrantes no passado e no presente: gênero, redes sociais e migração internacional". Revista Estudos Feministas, v. 15, n. 3, p. 745-772, 2007.

BENTO DE FARIA, Antonio. Annotações Theorico-praticas ao Codigo Penal do Brasil. Rio de Janeiro, 1929.

BLANCHETTE, Thaddeus Gregory; SILVA, Ana Paula da. “'Nossa Senhora da Help': sexo, turismo e deslocamento transnacional em Copacabana". Cadernos Pagu, n. 25, p. 249-280, 2005.

. "On Bullshit and the Trafficking of Women: Moral Entrepreneurs and the Invention of Trafficking of Persons in Brazil". Dialectical Anthropology, v. 36, p. 107-125, mai. 2012.

BRASIL. Decreto-Lei n. ${ }^{\circ} 2.848$, de 7 de dezembro de 1940. Código Penal. Presidência da República. Rio de Janeiro, 1940.

CASTILHO, Ela Wiecko Volkmer de. "A criminalização do tráfico de mulheres: proteção das mulheres ou reforço da violência de gênero?". Cadernos Pagu, n. 31, p. 101-123, dez. 2008. 
CHENG, Sealing. On the Move for Love: Migrant Entertainers and the U.S. Military in South Korea. Philadelphia: University Of Pennsylvania Press, 2010.

DOEZEMA, Jo. "Loose Women or Lost Women? The Reemergence of the Myth of 'White Slavery' in Contemporary Discourses of 'Trafficking in Women'". Gender Issues, v. 18, n. 1, p. 23-50, 2000.

FREDERICK, John. "The Myth of Nepal-to-India Sex Trafficking: its Creation, its Maintenance, and its Influence on Antitrafficking Interventions". In: KEMPADOO, Kamala; SANGHERA, Jyoti; PATTANAIK, Bandana (Eds.). Trafficking and prostitution reconsidered: new perspectives on migration, sex work, and human rights. Londres: Paradigm, 2005. p. 127-147.

GIL, Carmen Gregorio. "Trabajando Honestamente en Casa de Familia: entre la Domesticidad y la Hipersexualización". Revista Estudos Feministas, v. 15, n. 3, p. 699-716, 2007.

KEMPADOO, Kamala; DOEZEMA, Jo (Orgs.). Global Sex Workers. Rights, Resistance, and Redefinition. Nova lorque e Londres: Routledge, 1998.

MAI, Nick. "Embodied Cosmopolitanisms: the Subjective Mobility of Migrants Working in the Global Sex Industry". Gender, Place \& Culture, p. 1-18, jan. 2012.

PISCITELLI, Adriana. "Sexo tropical em um país europeu: migração de brasileiras para a ltália no marco do 'turismo sexual' internacional". Revista Estudos Feministas, v. 15, n. 3, p. 717-744, nov. 2007.

"Entre as 'máfias' e a 'ajuda': a construção de conhecimento sobre tráfico de pessoas". Cadernos Pagu, n. 31 , p. 29-63, jul. 2008.

"Revisiting Notions of Sex Trafficking and Victims". Vibrant: Virtual Brazilian Anthropology, v. 9, n. 1, p. 274310, 2012.

PISCITELLI, Adriana; LOWENKRON, Laura. "Categorias em movimento: a gestão de vítimas do tráfico de pessoas na Espanha e no Brasil". Ciência e Cultura, v. 67, n. 2, p. 35-39, 2015.

SHARMA, Nandita. "Anti-Trafficking Rhetoric and the Making of a Global Apartheid". NWSA Journal, v. 17, n. 3, p. 88111 , nov. 2005.

SILVA, Ana Paula da; BLANCHETTE, Thaddeus Gregory; BENTO, Andressa Raylane. "Cinderella Deceived: Analyzing a Brazilian Myth Regarding Trafficking in Persons". Vibrant: Virtual Brazilian Anthropology, v. 2, n. 10, p. 377-419, jul. 2013.

SPRANDEL, Marcia Anita; DIAS, Guilherme Mansur. "A temática do tráfico de pessoas no contexto brasileiro". Revista Interdisciplinar da Mobilidade Humana, n. 35, p. 155160, jul. 2010. 
SODERLUND, Gretchen. "Running from the Rescuers: New U.S. Crusades Against Sex Trafficking and the Rhetoric of Abolition". NWSA Journal, v. 17, n. 3, p. 64-87, set. 2005.

THORBEK, Susanne; PATTANAIK, Bandana (Orgs.). Transnational prostitution: changing global patterns. Londres e Nova lorque: Zed Books, 2002.

UNODC. United Nations Office on Drugs and Crime. Protocolo de Palermo, 2000. Disponível em: https://www.unodc.org/ unodc/treaties/CTOC/.

WEITZER, Ronald. "Miscounting human trafficking and slavery". Open Democracy, out. 2014. Disponível em: https:// www.opendemocracy.net/beyondslavery/ronald-weitzer/ miscounting-human-trafficking-and-slavery.

[Recebido em 23/04/2015, reapresentado em 12/05/2016 e aprovado em 25/06/2016]

\begin{abstract}
Human Trafficking for Sexual Exploration? An Analysis of Criminal Procedures (19952012)

Abstract: This article analyses Brazilian criminal procedures regarding human trafficking for sexual exploitation. The sources of research are 12 "cases" investigated/judged within 1995 and 2012. The methodology proposed is thought through feminist epistemologies. "Gender", "discursivity" and "subjectivation processes" are the analytical categories. This research shows how police practices to combat "human trafficking" have became a technique to fight prostitution and the prostitutes themselves.
\end{abstract}

Key words: Human trafficking; Sexual exploitation; Prostitution; Work.

Anamaria Marcon Venson (anamariamarconvenson@gmail.com) é graduada em História pela Universidade do Estado de Santa Catarina (UDESC) e em Direito pela Universidade Federal de Santa Catarina (UFSC); mestra em História e doutora em Ciências Humanas pelo Programa de Pós-Graduação Interdisciplinar, pela UFSC, com estágio doutoral na Universidade de Oxford (Inglaterra). Publicou artigos em diversas revistas acadêmicas e foi agraciada com o I Prêmio Libertas (Ministério da Justiça, Organização Internacional do Trabalho e Escritório de Drogas e Crimes das Nações Unidas) pelo trabalho Tráfico de pessoas em perspectiva histórica: uma análise do papel da imprensa. 